NASA Technical Memorandum 89916

AIAA-87-2122

\title{
In-Situ Analysis of Hydrazine Decomposition Products
}

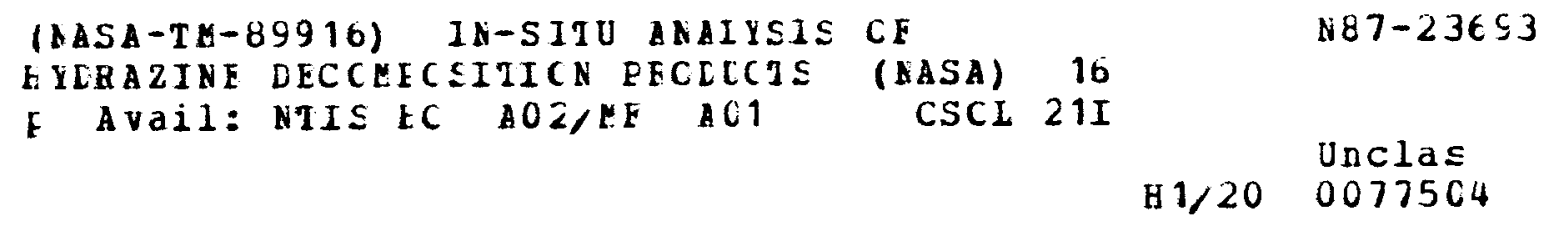

Francis M. Curran and Margaret V. Whalen

Lewis Research Center

Cleveland, Ohio

Prepared for the

23rd Joint Propulsion Conference

cosponsored by the AIAA, SAE, ASME, and ASEE

San Diego, California, June 29-July 2, 1987 


\section{IN-SITU ANALYSIS OF HYDRAZINE DECOMPOSITION PRODUCTS}

Francis M. Curran and Margaret $V$. Whaten

National Aeronautics and Space Administration

Lewis Research Center

Cleveland, Ohio 44135

\section{SUMMARY}

A gas analyzer utilizing a nondispersive infrared absorption (NDIR) detection system was used to monitor the ammonia and water vapor content of the products of a previously unused hydrazine gas generator. This provided an insitu measurement of the generators' efficiency difficult to obtain by other means. The analyzer was easily installed in both the calibration and hydrazine systems, required no maintenance other than periodic zero adjustments, and performed well for extended periods in the operating range tested.

The catalyst bed operated smoothly and repeatably during the $28 \mathrm{hr}$ of testing. No major transients were observed on startup or during steady state operation. The amount of ammonia in the output stream of the gas generator was found to be a strong function of temperature at catalyst bed temperatures beiow $450{ }^{\circ} \mathrm{C}$. At temperatures above this, the efficiency remained nearly constant. On startup the gas generator efficiency was found to decrease with time until a steady state value was attained. Elevated catalyst bed temperatures in the periods before steady state operation was found to be responsible for this phenomena.

\section{INTRODUCTION}

Liquid hydrazine is easily storable in space and can be decomposed exothermally to produce a gaseous mixture. These two qualities have made it the propellant of choice in a number of space-based propulsion systems. Applications range from the relatively high thrust (about 10 to $1300 \mathrm{~N}$ ) rockets used in attitude control, orbit correction, and station keeping (refs. 1 and 2) to the very low thrust ( 100 to $450 \mathrm{mN}$ ) resistojets used in north-south stationkeeping (ref. 3). Recently, high performance arcjets, to be run with existing, space qualified hydrazine propellant systems, have been proposed for the latter mission (ref. 4).

Monopropellant liquid hydrazine propellant feed systems employ a gas generator to convert the hydrazine to a gaseous mixture of hydrogen, nitrogen, and ammonia. While many types of gas generators exist, the most common are catalyst beds employing noble metals on an inert support. These are termed spontaneous catalysts as the hydrazine catalysis is initiated immediately upon contact and with no need for heating from an external source. By $f$ ar, the most useful to date has been the Shell 405 material, first introduced in 1963 (ref. 5). The decomposition process has been extensively reviewed by Schmidt (ref. 6). While the decomposition is best modeled by a two-step reaction scheme, the catalyst bed output at any point in time is given by the equation:

$$
3 \mathrm{~N}_{2} \mathrm{H}_{4} \rightarrow 4(1-x) \mathrm{NH}_{3}+(1+2 x) \mathrm{N}_{2}+6 x \mathrm{H}_{2}
$$

This paper is declared a work of the U.S. Government and is not subject to copyright protection in the United States. 
where $x$ is the ammonia dissociation fraction. The amount of ammonia remaining in the exit stream of the gas generator is used as a measure of the generator's efficiency.

Several degradation mechanisms have been identified which cause the efficiency to vary with time (ref. 6), and ultimately represent the limiting factor in system lifetime. Catalyst bed efficiency is also dependent on factors such as flow rate, which varies over the course of a typical mission due to blowdown pressure changes. Since performance determining factors such as average molecular weight (as determined by composition) depend on the efficiency of the gas generator, it is important to understand its variance with time in thruster systems currently in use. For the arcjet, variation in catalyst bed output is particularly important as small variations in propellant composition have been shown to affect the voltage/current characteristics of the thruster (ref. 7). Also, it is often convenient to test the arcjet with hydrogen/nitrogen/ammonia mixtures simulating hydrazine. For this to be valid, the mixture ratio must be known as a function of both flow rate and time.

Therefore, the ability to analyze the composition of the catalyst bed products at different flow rates over time is important to the arcjet application.

A number of methods exist to determine the composition of the output of a catalyst bed. Typically, samples are taken periodically and carried to a mass spectrometer or gas chromatograph for analyses. These methods are accurate, but inconvenient, as they do not lend themselves to rapid turnaround. In one study, a mass spectrometer and remote sampling device were used to sample thruster exhaust gases (ref. 8). Because stoichiometry of the decomposition process is known, determination of any of the three products fully determines the composition of the output. Many methods have been developed for the analysis of gaseous ammonia, but most of these are best suited for trace quantities (refs. 9 and 10). Nondispersive infrared absorption (NDIR) represents a simple method for the analysis of ammonia as a major constituent ( $>1$ percent by mole or volume).

In the present study, a commercially available IR system was installed in an existing hydrazine system for the in-situ analysis of ammonia in the catalyst bed exhaust. After calibration of the unit, a new spontaneous catalyst bed was tested for more than $28 \mathrm{hr}$ accumulated over seven separate test periods and at various flow rates. A separate channel also monitored the water vapor fraction in the output stream.

\section{APPARATUS}

A self-contained hydrazine system was used in this study. The system can be divided into 3 subsystems: the control and safety subsystems, the hydrazine feed subsystem and the gas analysis unit. A photograph of the entire experimental system is shown in figure 1 and a simplified schematic diagram is shown in figure 2 .

The control and safety subsystem included 2 interlocks to shut down the system in the event of a hydrazine leak. The first of these tied into the ventilation system. An exhaust fan, rated at 42151 iter/min, was installed to draw air through both the feed system container and the rack that held the gas 
analysis unit. A commercially available hydrazine detector continuously sampled the exhaust duct. In this, chemically treated paper is used for leak detection. Hydrazine vapor produces a color change in the paper and this change is sensed optically. In the event of a leak, the interlock was configured to sound an audible alarm, shut off the flow of liquid hydrazine and flood the hydrazine feed container with water to dilute any liquid hydrazine. The second interlock was keyed to the temperature of the inlet tube at the gas generator. Excessive heat soakback from the gas generator could cause the hydrazine to boil in the feed tube before reaching the gas generator and thus create an explosion hazard. The temperature set point on the interlock relay was set to a point below the $113.5^{\circ} \mathrm{C}$ bolling point of hydrazine. The relay was wired to shut down the flow of liquid hydrazine if the limit were exceeded.

The control and safety subsystems also included instrumentation that displayed several experimental parameters and conditions. Temperature measurements were taken both in the center of the gas generator body and on the inlet tube. For these, calibrated chromel-alumel thermocouples were used. Pressure readings both upstream and downstream of the gas generator were also displayed.

The hydrazine feed system consisted of a stainless steel hydrazine cylinder, a mechanical roughing pump and the gas generator. The hydrazine cylinder was pressurized by a cylinder of high purity nitrogen and the nitrogen supply could also be used to purge the system. The mechanical roughing pump was used to evacuate the system during the purges of the system performed at startup and shutdown. The hydrazine cylinder was $16.8 \mathrm{~cm}$ in diameter and $86.4 \mathrm{~cm}$ in length. The cylinder wall was $1.9 \mathrm{~cm}$ thick and had a rated working pressure of $1.24 \times 10^{8} \mathrm{~N} / \mathrm{m}^{2}$.

To insure hydrazine compatibility, stainless steel fittings and feed lines, and stainless steel valves with Teflon sealing surfaces were used throughout the system. Stainless steel solenoid valves were used both to open the hydrazine bottle and for pressurization of the cylinder.

The gas generator was a commercially avallable unit that used she 11405 as the spontaneous catalyst. The unit consisted of a capillary inlet tube with a copper heat sink and a short decomposition chamber containing the catalyst. The generator was plumbed into the feed system downstream of a needle valve used to provide control of the hydrazine mass flow rate.

For application to hydrazine decomposition product analys is, a nondispersive infrared (NDIR) system was chosen. This system had two channels in a series flow path, one for ammonia and one for water vapor. A simplified schematic for one channel is shown in flgure 3 , except for its electronics. In the analyzer, light from the IR source is split into two beams of equal intensity and these are directed down two identical optical paths leading to a detector. The reference path contains a sealed reference cell containing a gas that does not absorb in the IR while the sample path contains a sample cell through which the stream of hydrazine decomposition products flows $(0.5$ to $2.5 \mathrm{lpm})$. In each channel, the detector is made up of two compartments connected by a flow passage. Only the inner detector compartment is struck by the source radiation. A light chopper is used to bring light alternately from the sample and reference beams to this compartment. Thus, a full detector cycle consists of a reference half-cycle and a sample half cycle. The detector is completely sealed and filled with the gas under test, in this case ammonia on one channel. 
and water vapor on the other. For the purpose of illustration, the following discussion will concern only the ammonia channel. The water vapor channel operates in a similar manner.

Ammonia is the only IR absorber in the system. As no ammonia is present in the reference path, no absorption occurs on the reference half-cycle until the source radiation strikes the ammonia-containing detector cell. The absorbed radiation heats the gas in the inner detector compartment, the pressure in this compartment rises, and flow in the tube connecting the inner and outer detector compartments is sensed. If no ammonia is present in the sample compartment (e.g., if pure nitrogen is being used to purge the system) the same amount of source radiation heats the detector during the sample half cycle and the same flow is sensed. If, however, ammonia begins to enter the sample stream, the amount of heating in the detector during the sample half cycle decreases with respect to that seen in the reference half cycle. This leads to a drop in flow in the connecting tube during the sample half-cycle as compared to that sensed during the reference half-cycle. This decrease is linearly dependent on the concentration of ammonia in the sample stream.

The specifications given in tables I and II are manufacturer generated. The unit allowed two full scale ranges for each gas. The concentration ranges chosen for this application were 0 to 30 percent, switchable to 0 to 50 percent for the ammonia channel, and 0 to 5 percent, switchable to 0 to 10 percent for the water vapor channel.

As noted in the results, the accuracy of the gas analyzer was guaranteed only for flow rates between 0.5 and $2.51 \mathrm{pm}$. Because of this, the analyzer system was plumbed into the system as shown in figure 4 . A commercially avallable thermal conductivity flow meter was installed in the system just upstream of the analyzer to give a rough indication of the volume flow rate into the unit. In this arrangement, the flow could be split between the analyzer and the vent line to keep the flow to the analyzer below $2.5 \mathrm{lpm}$ when the total flow from the gas generator exceeded this limit. To protect the quartz IR cells, the effluent from the analyzer was exhausted directly to atmosphere and the temperature upstream of the unit was monitored continuousiy to insure the manufacturer specified value of $65^{\circ} \mathrm{C}$ was not exceeded.

A separate facility was used in the initial calibrations of the gas analyzer system. This has been described in detail elsewhere (ref. 7 ). Briefly, this was a small, cylindrical vacuum bell jar $(1.16 \mathrm{~cm}$ in diameter and $1.55 \mathrm{~cm}$ high) pumped by a large mechanical pump (20 $700 \mathrm{slpm})$. A commercially available, multichannel mass flow controller was used to control the flow of gases from cylinders containing nitrogen and mixtures of nitrogen, hydrogen and ammonia. These were mixed on a flow panel before entering the gas analyzer. The outlet of the analyzer was exhausted into the bell jar.

\section{PROCEDURE}

Before the initial calibration procedure for the NOIR unit was performed, both the nitrogen mass flow controller and the controller used for the ammonia, hydrogen and nitrogen mixtures were calibrated individually. Some uncertainty existed in the calibration of the mixtures as the flow controller was not made for these gases. This is discussed in more detall in the next section. To 
vary the ammonia content in the stream, the flow settings on the individual channels were simply varied to produce the desired mixture. Prior to testing in the hydrazine facility, the safety interlocks on the hydrazine system were checked, the hydrazine detector was turned on, and nitrogen was purged through the analyzer to eliminiate any ammonia or water vapor remaining in the lines from previous tests. Injtial analyzer readings were recorded. In order to monitor the instrumental drift, the channels were not rezeroed as a matter of course. Values obtained during the nitrogen purge after each experiment were simply subtracted from the values obtained during the experiment to give the values reported herein.

The hydrazine cylinder was pressurized to about $1.7 \times 10^{5} \mathrm{~N} / \mathrm{m}^{2}$ (25 psia) with ultrapure nitrogen ( 99.9995 percent). Once pressurized, the hydrazine flow was initiated via a needle valve, which controlled the total mass flow rate to the catalyst bed. Changes in mass flow rate were monitored with the flowmeter downstream of the catalyst bed and also by changes in the temperature of the catalyst bed. Flow rates above $2.51 \mathrm{pm}$ were handled by splitting the flow between the analyzer and exhaust vent as noted in the previous section. During the course of the testing, flow rates between about 0.5 and $7.01 \mathrm{pm}$ were used.

While data were recorded at selected intervals, the data reported as steady state were taken only after equilibrium values, at any set flow rate, were obtained.

Upon completion of each test session, the hydrazine flow was stopped by releasing the nitrogen pressure on the cylinder and closing the appropriate valves. The catalyst bed was allowed to cool to near room temperature to assure that all reactions had ceased. The system downstream of the hydrazine cylinder was then purged thoroughly with nitrogen, as was the analyzer, to check the post test readings. The gas generator was left isolated from the vent line to insure that no oxygen contamination of the catalyst could occur.

\section{RESULTS AND DISCUSSION}

\section{Calibration}

For calibration of the analyzer, two specialty gas mixtures of ammonia, hydrogen and nitrogen were purchased from a commercial source. By volume, one mixture contained 10.07 percent ammonia, 44.96 percent hydrogen, and 44.97 percent nitrogen, while the other contained 19.93 percent ammonia, 40.08 percent hydrogen, and 39.99 percent nitrogen. The compositions were determined gravimetrically by the supplier. When run directly into the gas analyzer, the first mixture produced readings of 9.9 to 10.1 percent ammonia over the manufacturers specified range of flow rates. A switch to the second mixture produced readings slightly higher than expected. At lower flow rates, the analyzer showed 20.5 percent and this rose to 20.7 at the $h$ igh end of the allowable flow rate range. This offset was not due to a zero drift, as the unit showed no trace of ammonia during the purges with ultrapure nitrogen performed both before and after the test. Two explanations exist: either the unit actually gave a high reading, or the gas mixture was siightiy off its specified value. As no independent check was run on the gas mixture, neither explanation can be positively ruled out. Further tests will be performed, but, 
at worst, this represents a 2 to 3 percent relative error in the unit's accuracy. Shown in figure 5 are data from tests in which nitrogen gas was added to the mixtures in order to vary the ammonia concentration in the flow to the analyzer. In the figure, the percentage of ammonia in the flow stream calculated from the flow meter readings is plotted versus the values observed on the gas analyzer. Ideally, this test should have produced a straight line with a slope of unity. While the data was very linear, the slope was calculated to be only 0.87 . The error in the slope is probably due to uncertainty in the calibration of the mass flow controller through which the mixtures were passed. This meter was not designed for use with this mixture but rather for pure ammonia. The fact that the analyzer gave reasonably accurate readings with the pure mixtures is further evidence of an error in the mass flow controller calibration. The linearity of the data indicates that the flow controller did read linearly with increasing flow rate and that the analyzer functioned properly over the range tested.

\section{Gas Generator Tests}

The gas generator was tested during eight separate test periods, on eight separate days, spread out over almost 3 months. The gas analyzer was left on for the majority of this period to provide an opportunity to check the longterm zero drift of the instrument. As expected, a small amount of drift was observed, but this was well within the manufacturers specifications. For periods of $24 \mathrm{hr}$ or less, the drift observed was negligible.

In the first test, the hydrazine flow control valve was set to a specific point and the system was allowed to come to equilibrium. Small adjustments in the valve setting were necessary to maintain a constant flow rate remains constant before a steady state reading was attained. The gas generator functioned smoothly throughout this brief test (approximately $1.5 \mathrm{hr}$ ) as no large excursions in temperature or flow rate were observed. In the next six tests, the system functioned in a similar manner. In these, flow rate was varied over a wide range in order to observe the effects of temperature on the composition of the gas generator output. Data from these seven test periods are presented in figure 6 . Here it can be seen that up to about $460^{\circ} \mathrm{C}$, the percentage of ammonia is strongly dependent on the temperatures of the catalyst bed. At low flow rates, where the bed temperature was between 280 and $300{ }^{\circ} \mathrm{C}$, the output was well over 30 percent ammonia by volume. Between 280 and $400{ }^{\circ} \mathrm{C}$, the decrease in the amount of ammonia was nearly linear with temperature, falling to about 18 percent at $400{ }^{\circ} \mathrm{C}$ with the percentage of ammonia reaching a minimum of about 10.8 at $470^{\circ} \mathrm{C}$. Very little. change was noticed over the next $50^{\circ}$. The temperature of the catalyst bed became convection 1 imited at approximately $520{ }^{\circ} \mathrm{C}$, so further increases in temperature via increases in the flow rate were not possible.

Further increases in flow, however, did not decrease the gas generator's efficiency as the ammonia content remained nearly constant (silightiy below 11 percent) to flow rates exceeding $0.06 \mathrm{~g} / \mathrm{sec}$. From this, it is apparent that flow rates of this magnitude did not cause overloading of the gas generator. This is a condition in which the mass flow per unit cross sectional area is high enough to overwheim the active catalyst sites. Had this occurred, the efficiency would have decreased with increasing mass flow rate. 
Some variation in the day-to-day output of the gas generator, under a given set of conditions, did exist. The scatter in the data taken with the temperature near $385{ }^{\circ} \mathrm{C}$ is the best example of this. While the mean value of the data taken falls at a point expected from an extrapolation of the data taken at lower catalyst bed temperatures, there is a scatter of about \pm 2 percent. This was much more than the random fluctuations seen in any given test (approximately \pm 0.2 percent). It should be noted that the lowest readings occurred in the first test period, and that without this data the range narrows to about \pm 1 percent. This may indicate a brief conditioning period at the onset of operation. Alternately, the difference may be due simply to a lack of experimental control on outlet pressure, flow rate, etc. Certainly, how. ever, there was no trend apparent in the data as readings taken on the last day of testing were seen to be nearly coincident with those taken in the second trial after only 2-1/2 $\mathrm{hr}$ of testing.

In the final test, the gas analyzer was used to monitor the catalyst bed output from the initiation of flow to the attainment of steady state. For this, the hydrazine mass flow rate was set at a specific value and then readjusted slightly over the first several minutes of the test in an attempt to maintain a constant flow. Both the percentage of ammonia in the output stream and the catalyst bed temperature are plotted versus time in figure 7 . The initial flow setting was higher than that at steady state. Consequently, the catalyst bed temperature was higher early on in the test and this caused the efficiency to decrease with time as the catalyst bed cooled off. From the plot, it can be seen that the ammonia concentration reached 90 percent of its steady state value in less than $14 \mathrm{~min}$ and 99 percent of its steady state value within $24 \mathrm{~min}$. The finite time taken to reach steady state indicates that variation in propellant composition should be expected during testing. This would be important in applications involving short duty cycle burns and in the simulation of hydrazine decomposition products.

The water content, as monitored by the second channel on the analyzer, did vary somewhat during testing. The water content of the hydrazine was specified as less than 1 percent. In most tests, the reading varied between 0.55 and 0.65 percent. Tests at low flow rates, in which the percentage of ammonia in the flow stream was high, produced readings as high as 0.95 percent. One possible explanation is that an overlap of absorption bands caused some interference on the water channel. This would be expected to be negligible at low ammonia concentrations and increase as the ammonia content increased. Further investigation of this phenomena is in progress.

\section{CONCLUOING REMARKS}

An NDIR gas analyzer was used to monitor the ammonia and water content in the output stream of a previousiy unused hydrazine gas generator that used She 11405 as the catalyst. The analyzer was easily installed in the system, required no attention other than minor periodic zero adjustment, and provided in-situ measurements of catalyst bed efficiency difficult to obtain with other methods. The gas generator was found to operate in a stable and repeatable fashion over the course of $28 \mathrm{hr}$ of testing conducted aver 3 months. Under the conditions of the tests, the efficiency of the catalyst bed, as measured by the ammonia concentration, was found to be a strong function of temperature for flow rates for which the catalyst bed temperature was less than about $450^{\circ} \mathrm{C}$. 
At temperatures above this, to the convection limit of about $520{ }^{\circ} \mathrm{C}$, the efficiency was essentially constant. In the tests designed to observe phenomena from onset of hydrazine flow to the steady state operating condition the efficlency was seen to decrease with time. This was caused by elevated catalyst bed temperatures due to initially elevated flow rates. The slow equilibration does indicate a need to account for variations in propeliant composition in short duration burns and in simulations of hydrazine decomposition products. During this period, a steady rise to the equilibrium condition was seen with no spikes or excursions in the concentration values.

In the range of flow rates typically used in auxiliary propulsion applications changes in flow rate on the order of $0.51 \mathrm{pm}$, the minimum flow rate necessary for analyzer accuracy, did change the catalyst bed efficiency significantly. This indicates that, at these low flow rates, operation of the analyzer and propulsion system would have to be used alternately for realistic results. For systems in which a change of $0.5 \mathrm{lpm}$ is negligible (i.e., high thrust applications), the unit could be used to provide a continuous monitor of the catalyst bed output.

Studies of the gas generator output in a vacuum environment will be necessary to provide accurate information for experiments utilizing mixtures to simulate hydrazine decomposition products. Extended testing will also provide information on variation in gas generator efficiency as the catalyst bed nears end of 1 ife.

\section{REFERENCES}

1. Smith, W.W., Nyberg, D.G., Wilson, W.W., and Hood, J.F. Jr., "Development and Design Aspects of a 5-Pound Thrust RCS Rocket Engine Module," AIAA Paper 70-65468, June 1970.

2. Gross, R.L., "Evaluation of the Walter Kidde 1335-Nt (300-1 $\left.b_{f}\right)$ Monopropellant Thruster," 1979 JANNAF Propulsion Meeting, Vol. 3, K.L. Strange, ed., CPIA-PUBL-300-VOL-3, Chemical Propulsion Information Agency, Laure1, MD, 1979, pp. 523-545.

3. McKevitt, F.X., "Design and Development Approach for the Augmented Catalytic Thruster (ACT)." AIAA Paper 83-1255, June 1983.

4. Knowles, S.C., Smith, W.W., Chun, S.I., and Feconda, R.T., "Low Power Hydrazine Arcjets: A System Description for Near-Term Application," 1986 JANNAF Propulsion Meeting, Vol. 1, K.L Strange and D.S. Eggleston, eds., CPIA-PUBL-455-VOL-1, Chemical Propulsion Information Agency, Laurel, MD, 1986, pp. 399-408.

5 Voge, H.H., "Catalyst for Monopropellant Decomposition of Hydrazine," Bulletin of the 5th Liquid Propulsion Symposium, CPIA PUBL-37A, Vol. Ill, Addendum, Chemical Propulsion Information Agency, Laure 1, MD, 1963, pp. $335-347$.

6. Schmidt, E.W., Hydrazine and Its Derivatives: Preparation, Properties, Applications, Wiley, New York, 1983. 
7. Hardy, T.L. and Curran, F.M., "Low Power dc Arcjet Operation with Hydrogen/Nitrogen/Ammonia Mixtures," AIAA Paper 87-1948, June 1987.

8. Shankar, V., Ram, K.A., and Bhaskaran, K.A., "Experimental Investigations of the $10 \mathrm{~N}$ Catalytic Hydrazine Thruster," Acta Astronautica, Vol. 12, No. 4, Apr. 1985, pp. 237-249.

9. Kato, A., Uno, S., Kamo, T., and Matsuda, S., "Continuous Gaseous Ammonia Analyzer by Gas Titration Method," Review of Scientific Instruments, Vol. 55, No. 11, Nov. 1984, pp. 1823-1826.

10. Wilson, C.L. and Wilson, D.W., Comprehensive Analytical Chemistry, Elsevier, New York, 1959.

TABLE I. - GENERAL DESCRIPTION OF NDIR ANALYSER

\begin{tabular}{|l|}
\hline \multicolumn{1}{|c|}{ General Descriptions } \\
\hline Full 19 in. rack mountable unit $(19 \times 6 \times 14 \mathrm{~d})$, approximately 30 lbs \\
NDIR optics \\
Stainless steel gas tubing \\
Series gas path connections (can be arranged in paralle 1$)$ \\
$10 V ; 0$ to $20 \mathrm{~mA}$ signal outputs (1inear) \\
$110 v$ power requirement \\
Digital displays \\
Thermostated optical portion at $65{ }^{\circ} \mathrm{C}$ \\
$1 / 4 "$ stainless steel inlet/outlet connections \\
Stainless steel screwed gas path connections \\
\hline
\end{tabular}

TABLE II. - SPECIFICATIONS OF NDIR ANALYSER

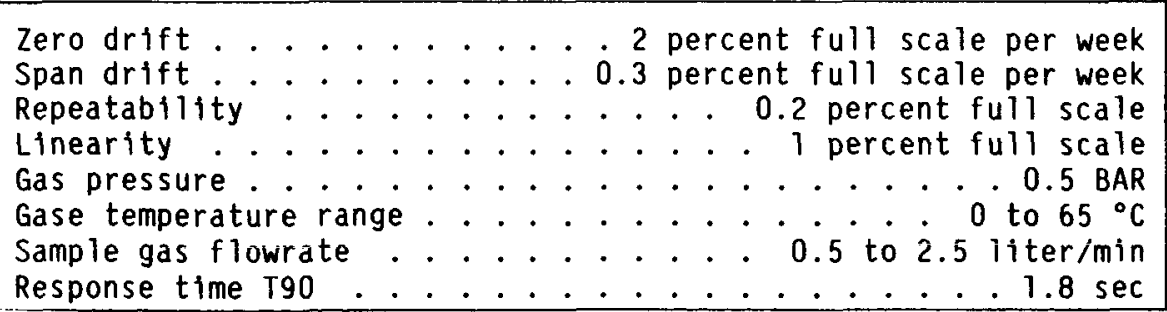




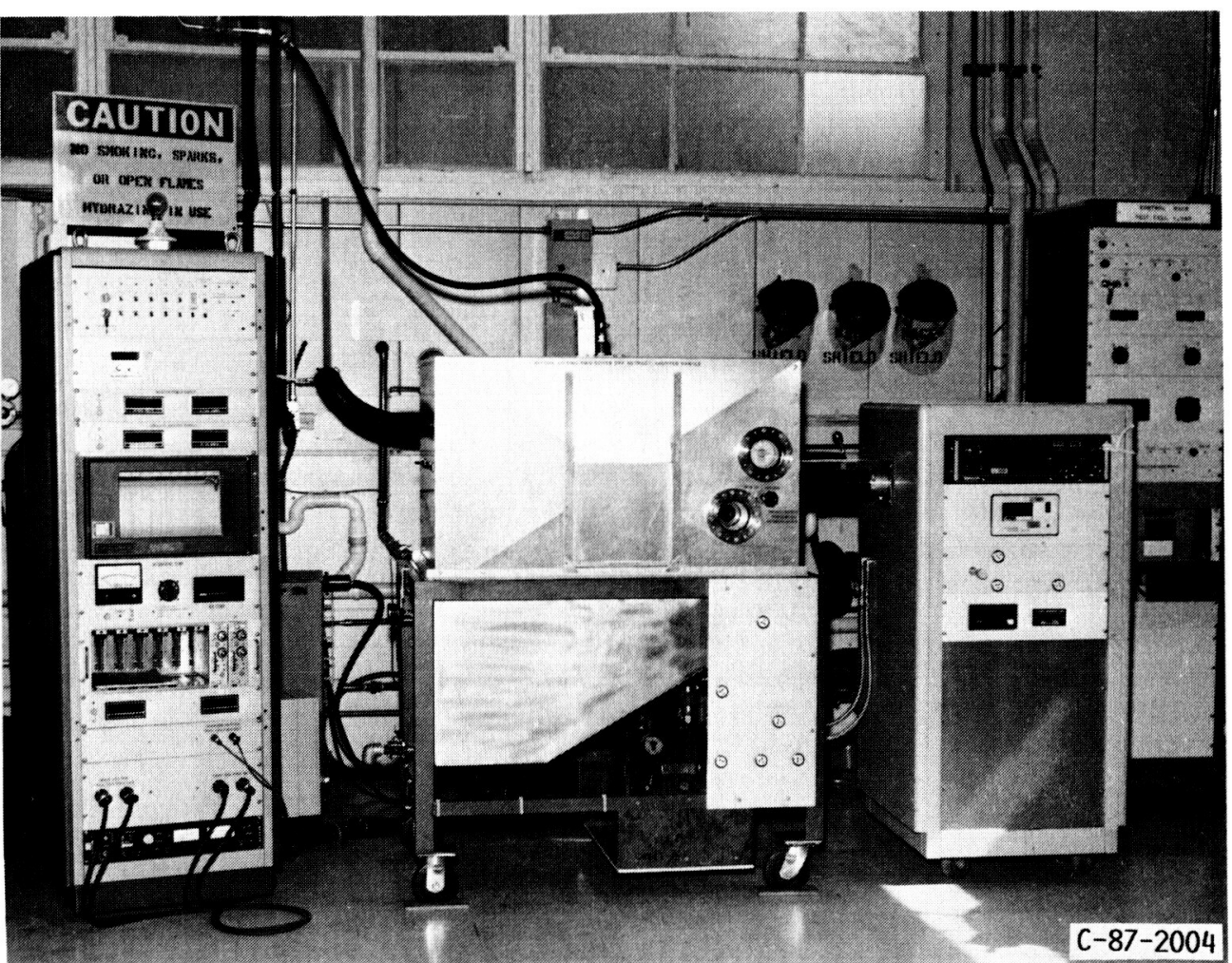

FIGURE 1. - PHOTOGRAPH OF THE HYDRAZINE/ANALYZER SYSTEM. 


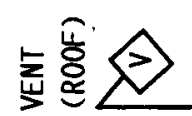

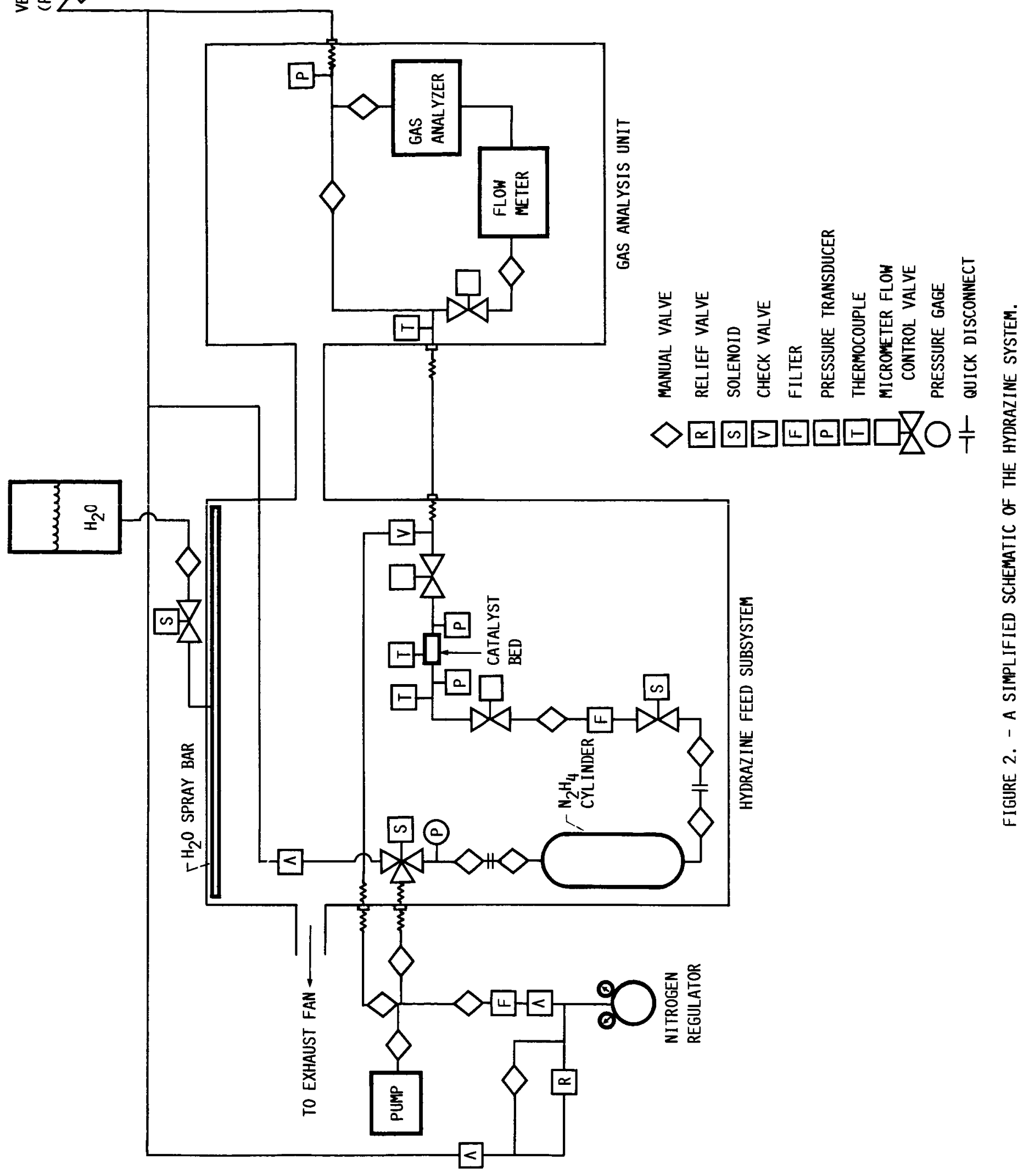


1. INFRARED SOURCE.

2. REFLECTOR.

3. CELL HOUSING.

4. CELL, SAMPLE SIDE.

5. CELL, REFERENCE SIDE.

6. GAS FILTER.

7. CHOPPER WHEEL.

8. DCTECTOR, OUTER COMPARTMENT.

9. DETECTOR, INNER COMPARTMENT.

10. DETECTOR CONNECTING TUBE.

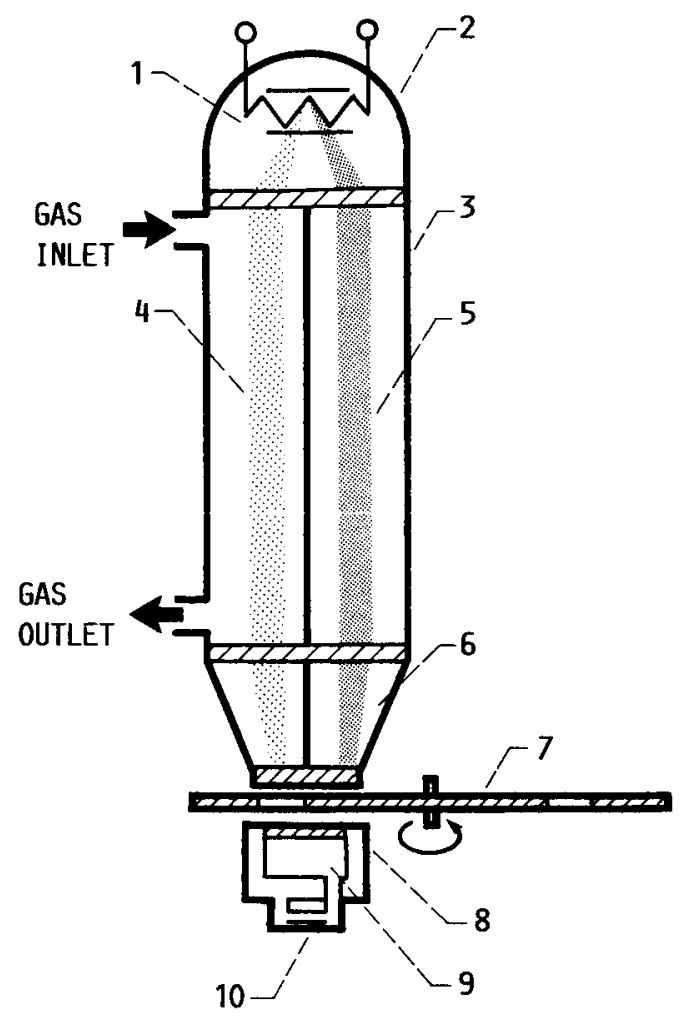

FIGURE 3. - SIMPLIFIED SCHEMATIC OF ONE CHANNEL OF THE NDIR SYSTEM.

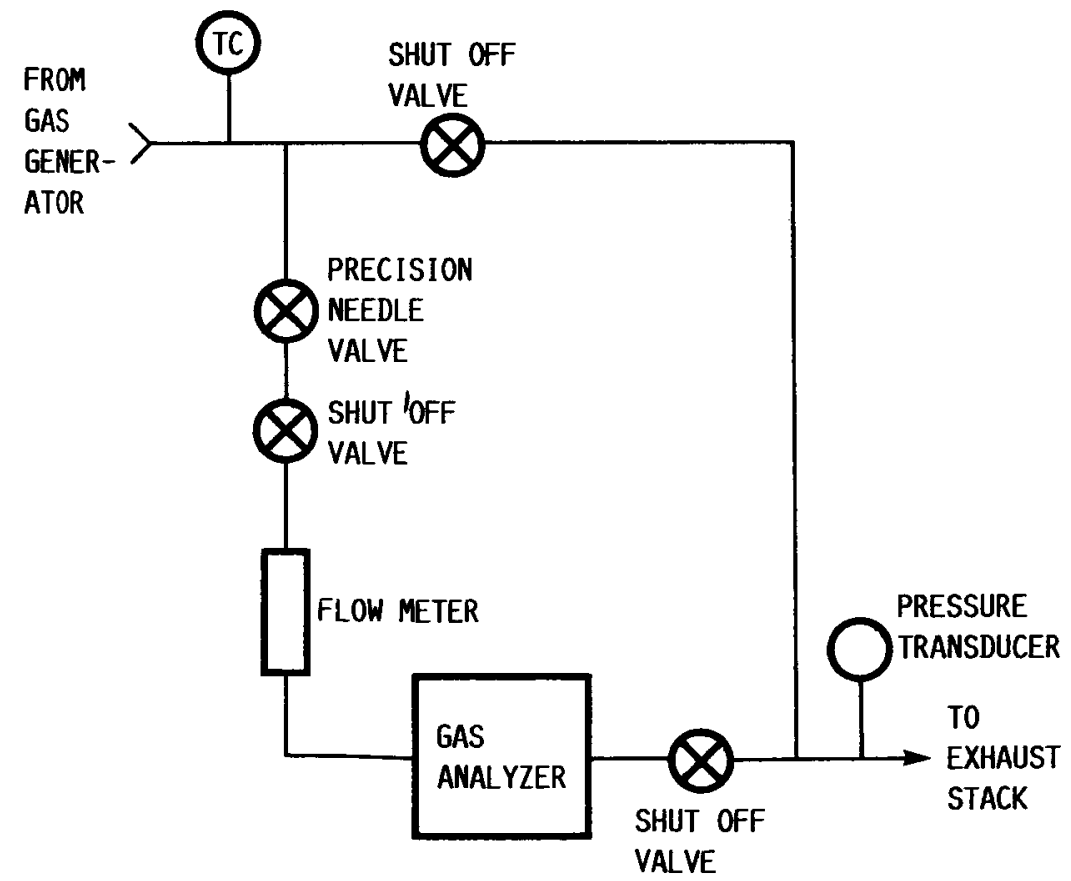

FIGURE 4. - SCHEMATIC DIAGRAM OF SUBSYSTEM CONTAINING GAS ANALYZER. 


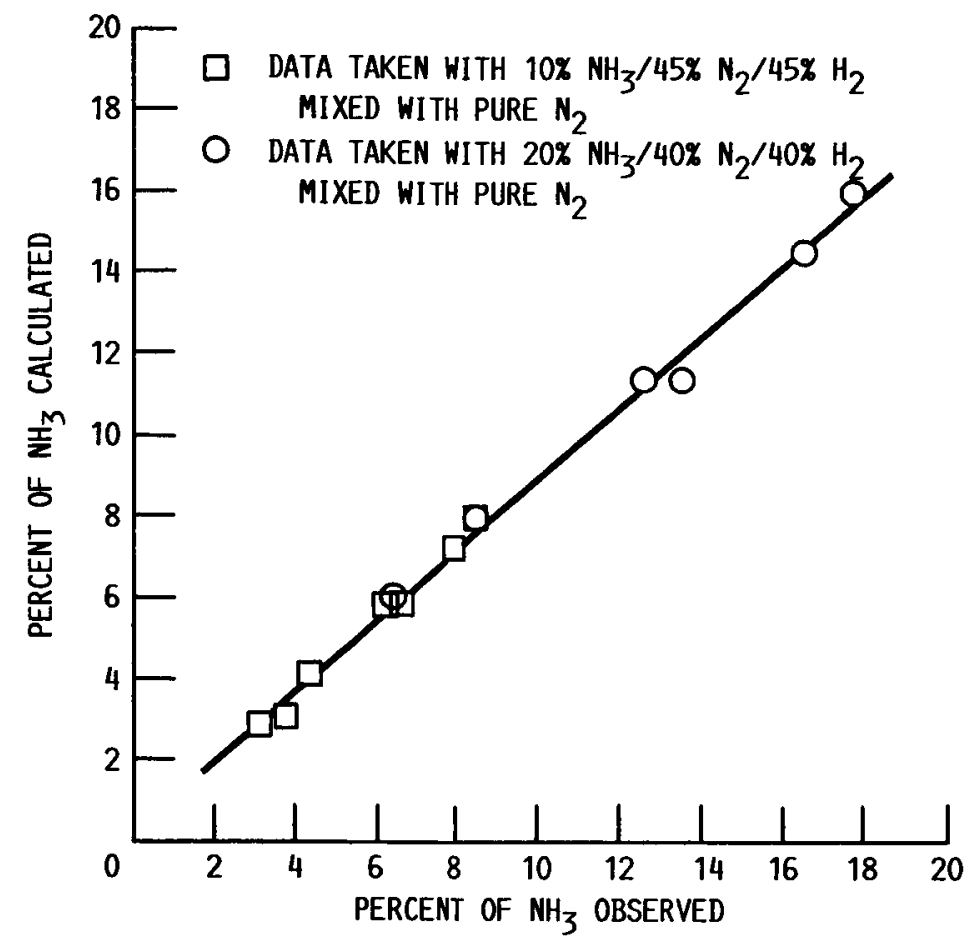

FIGURE 5. - PERCENT OF $\mathrm{NH}_{3}$ IN STREAM CALCULATED VERSUS OBSERVED FOR CALIBRATED MIXTURES.

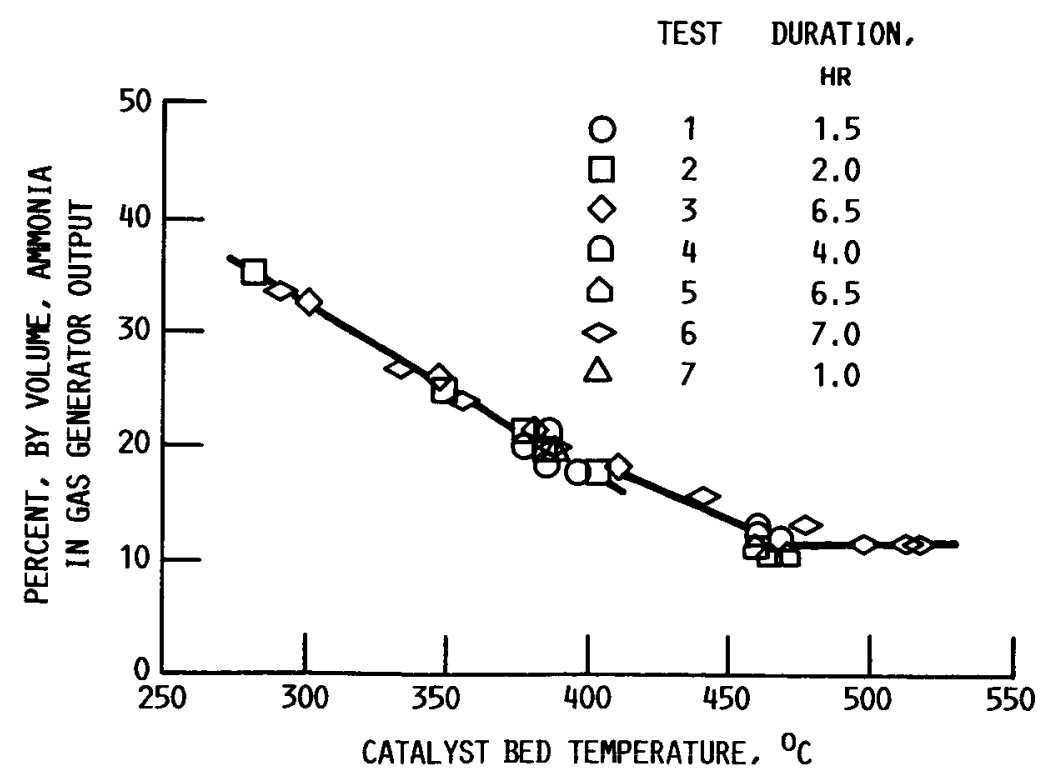

FIGURE 6. - CATALYST BED OUTPUT VERSUS TEMPERATURE. 


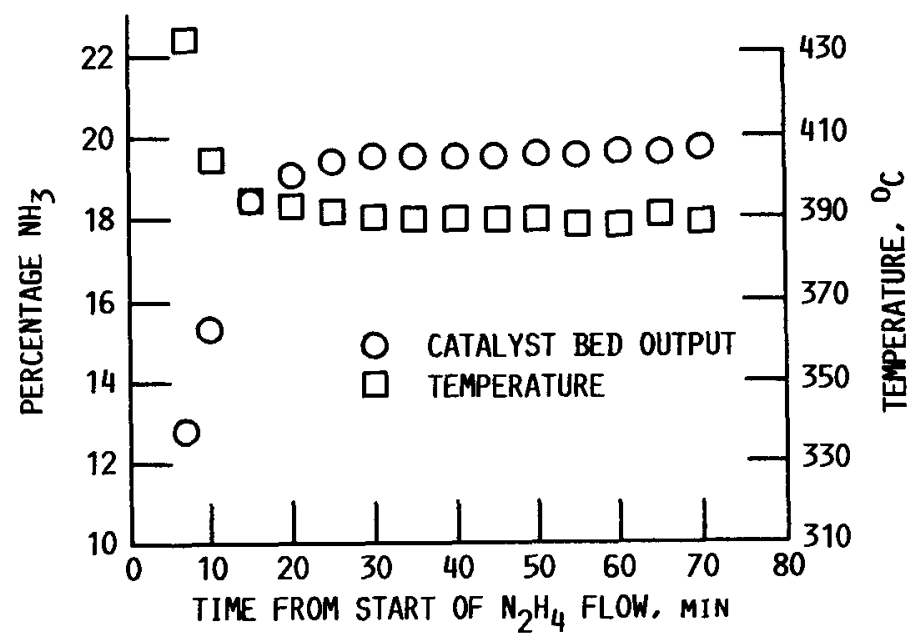

FIGURE 7. - CATALYST BED OUTPUT AND TEMPERATURE VERSUS TIME. 


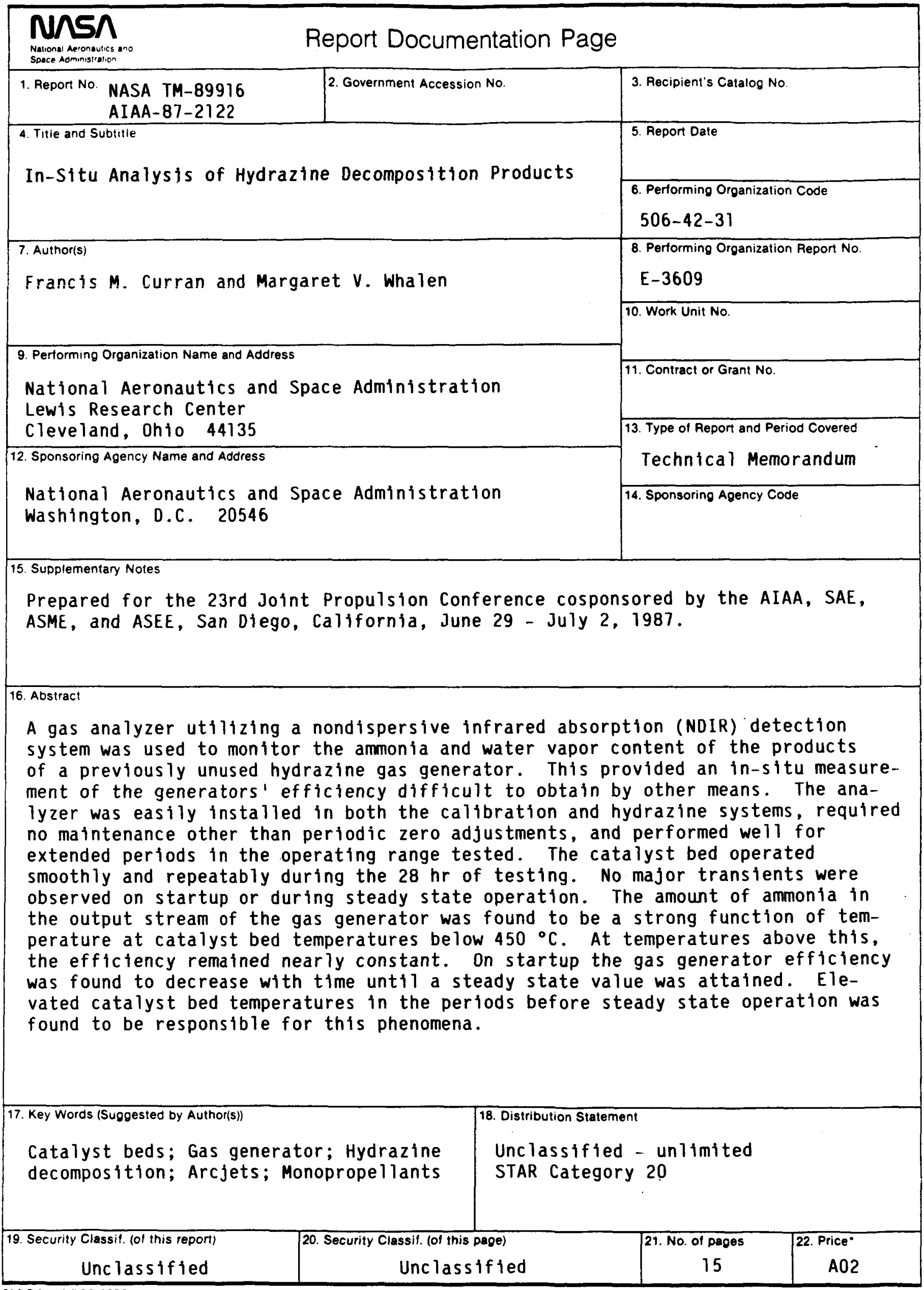

NASA FORM 1626 OCT 86 "For sale by the National Technical information Service, Springfield, Virginia 22161 